\title{
Incidence of Type 1 (insulin-dependent) diabetes mellitus in subjects 0-14 years of age in the Comunidad of Madrid, Spain
}

\author{
M.Serrano Ríos ${ }^{1}$, C.S.Moy ${ }^{3}$, R.Martín Serrano ${ }^{1}$, A.Minuesa Asensio ${ }^{1}$, M.E.de Tomás Labat ${ }^{1}$, G. Zarandieta \\ Romero ${ }^{1}$ and J.Herrera ${ }^{2}$ \\ ${ }^{1}$ Hospital Clínico San Carlos, Universidad Complutense, ${ }^{2}$ Instituto Diabetológico, Madrid, Spain, and ${ }^{3}$ Department of Epidemiology, \\ University of Pittsburgh, Pittsburgh, Pennsylvania, USA
}

\begin{abstract}
Summary. A retrospective, population-based registry was established in the Comunidad of Madrid, Spain (total population: $4,780,572$; under age $15: 1,105,243$ ) to investigate the epidemiology of Type 1 (insulin-dependent) diabetes mellitus. Included were all cases diagnosed with diabetes between 1985 and 1988, with age onset less than 15 years, and using insulin at discharge from hospital. Using the capture-recapture method employing hospital records as the primary source and membership files of the Spanish Diabetic Association as the secondary source, the ascertainment was $90 \%$. The overall annual incidence was estimated to be $11.3 / 100,000$ (Poisson $95 \%$ confidence interval: $10.3-12.4$ ). There was no tem-
\end{abstract}

poral increase in incidence, nor was there a significant sex difference in incidence rates, either overall or by year. The seasonal onset pattern showed the highest incidence in winter (December-February) and lowest in summer (June-August) $(r=7.36, p<0.05)$. The age-adjusted (world standard) incidence of $10.9 / 100,000$ was inconsistent with the hypothesis of a north-south gradient in diabetes risk.

Key words: Type 1 (insulin-dependent) diabetes mellitus, incidence, childhood, epidemiology, registry, geographic pattern.
In recent years epidemiological studies throughout the world have discovered that the incidence of Type 1 (insulin-dependent) diabetes mellitus demonstrates considerable ethnic and geographic variation as well as evidence of a global increase. Therefore, to evaluate the incidence of childhood diabetes in more diverse populations throughout the world is an indispensable step in the study of the aetiopathogenesis of this disorder. The purpose of this paper is to report the results of the first incidence data of diabetes mellitus in Spanish children 0-14 years of age.

\section{Subjects and methods}

A registry of Type 1 diabetic patients was established in the Comunidad of Madrid (the official name for the city and its province), whose population, according to the 1986 census counted 4.7 million inhabitants, $23 \%$ of whom (1.1 million) are less than 15 years of age [1].

\section{Case definition and data collection}

The registry was retrospective. Only newly diagnosed Type 1 cases were included. The definition of a case for the registry was: any individual diagnosed with Type 1 diabetes between January 1,1985 and
December 31,1988 who was less than 15 years old and using insulin at diagnosis and was resident of the Comunidad of Madrid.

Hospital records were the primary source of data in the 13 centres with a Service/Section for Paediatrics and/or Paediatric Endocrinology, each one serving a well-defined area in the health care delivery system of the Comunidad of Madrid. The membership file of the Spanish Diabetic Association, was used as the secondary source for validation of case ascertainment.

\section{Statistical analysis}

To establish the completeness of ascertainment and to estimate the true number of cases in Madrid, the capture/recapture method was employed [2]. The estimated number of cases (corrected for underascertainment) was used for the calculation of total incidence as well as for the comparison of incidence according to sex or year of diagnosis. For other subgroup comparisons, the actual (uncorrected) number of cases was used because the small number of cases in some of the categories resulted in unstable estimates. For comparison with data from other countries, the incidence was standarised by the direct method [3] according to the age distribution of the world population [4]. Confidence intervals for incidence rates were calculated using the Poisson approximation [5]. Seasonality of diagnosis was also examined in this population. In order to smooth the seasonal trend data, a three-month moving average was computed. Tests for seasonal trend in onset employed the method described by Roger [6]. 
Table 1. Number of cases and completeness of case ascertainment for primary source (hospitals) and secondary source (Spanish Diabetic Association), Madrid, 1985-1988

\begin{tabular}{lllllll}
\hline & \multicolumn{2}{l}{ No. of cases (\% of total estimated) } & \multicolumn{2}{l}{$\begin{array}{l}\text { Total esti- } \\
\text { mated ca- } \\
\text { Year }\end{array}$} & Primary & \multicolumn{2}{l}{ Secondary Both } & $\begin{array}{l}\text { One } \\
\text { or both }\end{array}$ & ses $^{\text {a }}$ \\
\hline 1985 & $104(85)$ & $48(39)$ & $41(34)$ & $111(91)$ & 123 \\
1986 & $100(83)$ & $47(39)$ & $39(33)$ & $108(90)$ & 120 \\
1987 & $114(88)$ & $16(12)$ & $14(11)$ & $116(90)$ & 129 \\
1988 & $114(93)$ & $27(22)$ & $25(20)$ & $116(94)$ & 123 \\
$1985-1988$ & $432(86)$ & $138(28)$ & $119(24)$ & $451(90)$ & $501^{\text {b }}$ \\
\hline
\end{tabular}

a Calculated from method in [2]. ${ }^{b}$ Estimate of total derived from aggregate data differs slightly from sum of yearly estimates

\section{Results}

The number of cases and their distribution in the primary and secondary sources, as well as their ascertainment rates overall and by year of diagnosis, are presented in Table 1. The overall ascertainment of the Madrid registry was estimated to be $90 \%$.

The estimated number of cases, estimated incidence overall and standardised (world population) per year and by sex during the period 1985-1988 are shown in Table 2 . No differences were observed according to year or sex in the unadjusted nor in the standardised incidence. Incidence by sex and age group was nearly identical for males and females less than age 10 years $(7 / 100,000$ in subjects $0-4$ years of age and about $9 / 100,000$ among those $5-$ 9 years of age). The incidence was higher among adolescent males than females $(14.5 / 100,000$ and $12.2 / 100,000$, respectively), although the difference was not statistically significant. Temporal trends in annual incidence by year and age at diagnosis in males and in females are shown in Figure 1. Slight changes were observed in males in both 10-14 and 5-9 age groups. In boys 0-4 years old, the incidence decreased abruptly from 1985 to 1987, later returning to close to the 1985 incidence rates. Annual incidence fluctuated from year to year in females $0-4$ and 5-9 years of age, whereas an initially rapid increase later levelling off in 1987 was observed in those in the older group (10-14 years). In both males and females, the peak age of diagnosis was around the age of puberty, between age 10 and 12 years. There was also a suggestion of an early peak at age 3 years, followed by a plateau between ages 4 and 8 years.

With respect to seasonal pattern in the total population (not shown), the lowest incidence was found between June and August, with higher incidence in late autumn (October) and winter (November-February) $(r=7.36$, $p<0.05)$. The seasonal pattern was strongest in cases diagnosed in 1987 and $1988(r=5.77, p<0.10$, and $r=6.6$, $p<0.05$, respectively). By age at diagnosis (data not shown) the youngest group (0-4 years) showed two peaks of incidence in spring and late autumn, with a nadir by the end of July and August.

\section{Discussion}

Epidemiologic data concerning Type 1 diabetes in Spain are very scarce. The only other relevant data are from the area surrounding Barcelona, which reported a similar incidence to Madrid; however, that study has not yet been validated. Therefore, our work has established the first standard registry of childhood diabetes in Spain in a large representative sample of the population.

The present registry was developed according to the standardised approach discussed by LaPorte [8] permitting comparison with registries at the international level. To estimate the degree of ascertainment, we used the capture-recapture methodology which yields much better estimates of the actual incidence than by not using any secondary source.

Our estimated incidence of 11.3/100,000/year in Madrid was intermediate between the high rates reported in northern European countries, such as Finland, Sweden, Norway, Scotland, and Denmark, and in the low-incidence Mediterranean countries such as Israel [9] but similar to those reported in Luxembourg [10], the Netherlands [9] and in Italy [11], although higher than in France [9].

In contrast to most other populations $[12,13]$, in which onset in females tends to peak a few years earlier than males, in Madrid the age at diagnosis patterns were similar for males and females. There was no evidence of a male excess in any age subgroup such as that indicated by the study in Luxembourg [10]. A trend of increasing incidence of diabetes has been noticed in Europe and in some nonEuropean countries [14], but in our study a temporal increase in incidence was not found.

Table 2. Estimated number of cases, estimated incidence, and standardised incidence of Type 1 (insulin-dependent) diabetes mellitus according to year of onset and sex, Madrid, 1985-1988

\begin{tabular}{|c|c|c|c|c|c|c|}
\hline & $\begin{array}{l}\text { Estimated } \\
\text { no. } \text { cases }^{\mathrm{a}}\end{array}$ & $\begin{array}{l}95 \% \\
\mathrm{CI}^{\mathrm{a}, \mathrm{b}}\end{array}$ & $\begin{array}{l}\text { Incidence } \\
/ 100,000\end{array}$ & $\begin{array}{l}95 \% \\
\mathrm{CI}^{\mathrm{b}}\end{array}$ & $\begin{array}{l}\text { Stand, incidence } \\
/ 100,000^{c}\end{array}$ & $\begin{array}{l}95 \% \\
\mathrm{CI}^{\mathrm{b}}\end{array}$ \\
\hline Total & 501 & $472-523$ & 11.3 & $10.3-12.4$ & 10.9 & $9.9-11.9$ \\
\hline Female & 234 & $212-255$ & 10.9 & $9.5-12.5$ & 10.5 & $9.1-12.0$ \\
\hline Male & 267 & $249-285$ & 11.8 & $10.4-13.4$ & 11.3 & $9.9-12.8$ \\
\hline \multicolumn{7}{|c|}{ Year of diagnosis } \\
\hline 1986 & 120 & $108-132$ & 10.9 & $9.0-13.2$ & 10.3 & $8.5-12.5$ \\
\hline 1987 & 129 & $109-150$ & 11.7 & $9.7-14.0$ & 10.6 & $8.8-12.8$ \\
\hline 1988 & 123 & $112-134$ & 11.1 & $9.2-13.4$ & 10.6 & $8.8-12.8$ \\
\hline
\end{tabular}

a Based on method in [2]; ${ }^{b}$ Poisson confidence interval (CI), [5]; ${ }^{c}$ Standardised to world population, [4] 


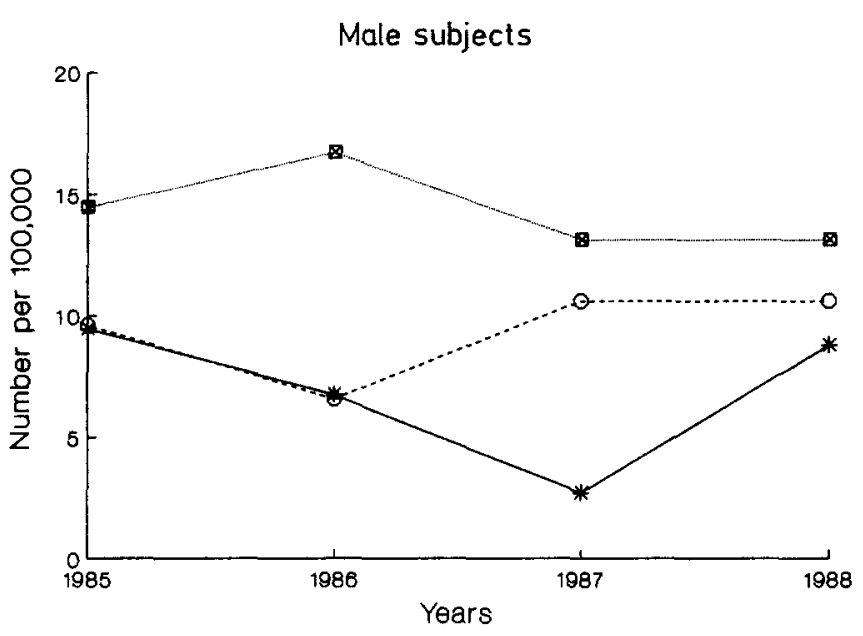

Female subjects

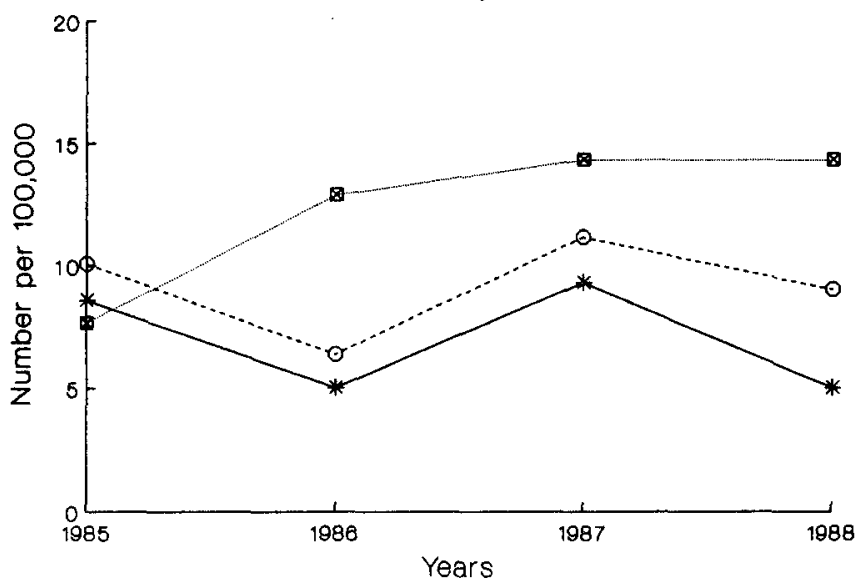

Fig. 1. Annual incidence of Type 1 (insulin-dependent) diabetes in Madrid, by year of diagnosis and age group. $-*-0-4-O-5-9-\square-$ 10-14

In the Madrid population, the typical overall seasonal pattern was observed, with the highest proportion of cases diagnosed in the winter months of November through January and the fewest cases in June, July and August.

Our study is the first in Spain, and one of the first in Southern Europe, to investigate childhood diabetes using a validated epidemiologic methodology. The higher than expected incidence in Madrid is not consistent with the hypothesis that a latitude (North-South) gradient may be of major importance as an explanation of the wide geographical variations in the incidence of diabetes observed in Europe and worldwide. Of further importance, our population and the methods employed in Madrid will provide a valid reference source for establishing comparative research in the populations of the Americas that share a Spanish heritage, yet with varying degrees of admixture with other ethnic groups and living under very different environmental conditions [15].

Acknowledgements. This work was supported in part by NIH grant R01 DK24021 and a grant from the Fundación Valgrande. The official support of Dr. P. Sabando, the Health Advisor of the Comunidad de Madrid is gratefully acknowledged. The authors also wish to thank Dr. R. LaPorte and Dr. J. Dorman of the WHO Collaborating
Center for Diabetes Registries in Pittsburgh, Pennsylvania, USA; Dr. J.R.Repullo and C.G.Asorey, Scientific Advisors of the Comunidad de Madrid; Dra. V.Zunzunegui, epidemiologist and Dr. F.Pozo of the Fondo de Investigaciones Sanitarias de la Seguridad Social; Sra. N. Alfageme, President of the Asociación Española de Diabéticos; as well as the Madrid IDDM Study Group, including all the hospitals of the Comunidad of Madrid collaborating in this study.

\section{References}

1. Anuario Estadístico 1987. Vol.1. Comunidad de Madrid, Spain

2. Cochi SL, Edmonds LE, Dyer K, Graeves WL, Marks JS, Rovira EZ, Preblud SR, Orenstein WA (1989) Congenital rubella syndrome in the United States, 1970-1985: on the verge of elimination. Am J Epidemiol 129:349-361

3. Breslow NE, Day NE (1987) Statistical methods in cancer research. Vol. II - The design and analysis of cohort studies. Lyon, IARC Scientific Publications no.82, International Agency for Research on Cancer, pp 53-55

4. Vu MT (1985) World Population Projections 1985. The Johns Hopkins University Press, Baltimore, $\mathrm{p} 7$

5. Lilienfeld AM, Lilienfeld DE (1980) Foundations of epidemiology. Oxford University Press, Oxford, pp 336-338

6. Roger JH (1977) A significance test for cyclic trends in incidence data. Biometrika 64: 152-155

7. Guasch M, Anglada J, Arroyo J, Rodríguez M, Tabau M, Garau X (1988) Epidemiology of Type 1 (insulin-dependent) diabetes in Terrassa (160,106 inhabitants), Barcelona: its correlation with ongoing viral infections in the community. Diabetologia 31: 522 (Abstract)

8. LaPorte RE, Tajima N, Åkerblom HK, Berlin N, Brosseau J, Christy M, Drash AL, Fishbein H, Green A, Hamman R, Harris M, King H, Laron Z, Neil A (1985) Geographic differences in the risk of insulin-dependent diabetes mellitus: the importance of registries. Diab Care 8 [Suppl 1]: 101-107

9. Diabetes Epidemiology Research International (1988) Geographic patterns of childhood insulin-dependent diabetes mellitus. Diabetes 37:1113-1119

10. de Beaufort CE, Michel G, Glaesener G (1988) The incidence of Type 1 (insulin-dependent) diabetes mellitus in subjects aged 0-19 years in Luxembourg: a retrospective study from 1977 to 1986. Diabetologia 31: $758-761$

11. Pagano G, Cavallo-Perin P, Cavalot F, Dall'omo A, Masciola P, Suriani R, Amoroso A, Curtoni S, Borelli I and Lenti G (1987) Genetic, immunologic, and environmental heterogeneity of IDDM: incidence and 12-mo follow-up of an Italian population. Diabetes 36: 859-863

12. Schober E, Frisch H (1988) Incidence of childhood diabetes mellitus in Austria 1979-1984. Acta Pædiatr Scand 77:299-302

13. Dahlquist G, Blom L, Holmgren G, Hägglöf B, Larsson Y, Sterky G, Wall S (1985) The epidemiology of diabetes in Swedish children 0-14 years - a six-year prospective study. Diabetologia 28 : $802-808$

14. Bingley PJ, Gale EAM (1989) Rising incidence of IDDM in Europe. Diab Care 12: 289-295

15. Diabetes Epidemiology Research International Group (1989) Evaluation of epidemiology and immunogenetics of IDDM in Spanish- and Portuguese-heritage registries: a key to understanding the etiology of IDDM? Diab Care 12: 487-493

Received: 12 September 1989

and in revised form: 14 February 1990

Prof. M. Serrano Ríos

Hospital Clínico

Department of Internal Medicine

Ala Norte, Planta $6^{a}$

c/ Martín Lagos s.n.

E-28040 Madrid

Spain 